\title{
Overt versus covert rehearsal in short-term memory'
}

Following two silent rehearsals, lists were better recalled than they were following two voiced rehearsals, but there was no interaction between voicing at presentation and voicing during rehearsal. These results held both for forcedorder and semi-free order recall, though in the latter recencyeffects were enhanced following unvoiced rehearsal. The findings are discussed with respect to the feasibility of using overt rehearsal as a means of investigating rehearsalprocesses in general.

When a list is presented for short-term recall, $\mathrm{S}$ will sometimes try to rehearse parts of the list as it appears, but will then nearly always rehearse the whole list (or most of the list, depending on his strategy) in the interval between presentation and recall. Since post-list rehearsal is subvocalized, it can only be examined indirectly. One method of doing so would be to ask $S$ to rehearse "aloud" so that his responses can be recorded. The purpose of this paper will be to report a study in which recall following covert rehearsal was compared with recall following overt rehearsal: the aim was to discover whether recall under these two conditions would differ in any way important enough for the "overt" method of investigating rehearsal to be invalidated. The variable of overt vs. covert responding at presentation was also examined, in order to see whether there was an interaction between the vocalization level used at presentation and that used in rehearsal. Recall was either forced-order or semi-free, as strategies of rehearsal might well differ according to the type of recall required; in previous work (Murray, 1966) it had been incidentally noted that in semi-free recall some Ss adopted the strategy of recalling the most recent items first, rather than that of starting recall at the beginning of the list.

\section{Method}

Lists of eight consonants, drawn from those used by Murray (1966), were typed onto a roll of paper which could be fed through a memory-drum (continuous movement) at a rate corresponding to two letters/sec. There were 32 lists on the roll, divided into four groups of eight. As the material was presented, S either read each letter aloud (V, "vocalize") or silently read it (R, "read"). He then either rehearsed the list twice aloud, with a third rehearsal constituting the "recall" list, or rehearsed twice silently, giving the third rehearsal aloud. In both cases, only the third list was scored for recallaccuracy, the index being the number of letters recalled in their correct position. The four conditions, which will be called VV and VR, RV and RR respectively, were counterbalanced across the four groups of letters in the roll, so that each $\mathrm{S}$ did eight lists under each condition.

In Experiment I all recall was forced-order, i.e., $S$ had to start his recall at the first letter and work through without omissions to the eighth letter. In Experiment II, the conditions and design were exactly as for Experiment I except that recall was semifree, i.e., $S$ could start his recall at any letter, and could leave omissions, but had to verbally specify the position of each recalled letter. He could, for example, say "the last four were so-and-so, the first letter was so-and-so, the rest I can't remember." As $S$ recalled, E wrote down his recall in a prepared matrix (this was found quite easy to do without errors).

In each experiment, the Ss were 24 undergraduates from introductory psychology classes at Queen's University.

\section{Results and Discussion}

Figure 1 shows the data for both experiments, broken down into a serial position analysis. Dealing first with the overall totals, not counting serial position, it was found that in both experiments voicing at presentation gave superior recall to silent reading at presentation (Experiment I: $F=6.75, \mathrm{df}=1 / 23, \mathrm{p}<.05$; Experiment II: $F=5.31, d f=1 / 23, p<.05)$. In both experiments, silent rehearsal was superior to voiced rehearsal (Experiment I: $F=8.44, \mathrm{df}=1 / 23, \mathrm{p}<.01$; Experiment II: $F=18.44, d f=1 / 23, p<.001)$. And in neither experiment was there a significant interaction between the mode of voicing at presentation and the mode of voicing in rehearsal. The advantage for vocalization-at-presentation confirms previous work, as does the advantage of semi-free over forced recall (see Murray, 1966).

With respect to serial position effects, it is clear, from both graphs of Fig. 1, that voicing-at-presentation led to more pronounced recency effects than did silent reading at presentation, another finding supporting the results given in the 1966 paper. It would also seem however that in forced recall the extent of the recency effect varied little with whether rehearsal was voiced or not, whereas in semi-free recall, the size of the recency effect was in general reduced when rehearsal was voiced aloud (comparing scores on position 8 on VR and VV, for example, a signs-test yielded $p=.067)$. The greater recency effects noted in Experiment II as compared with Experiment I resulted mainly from the fact that in Experiment II 

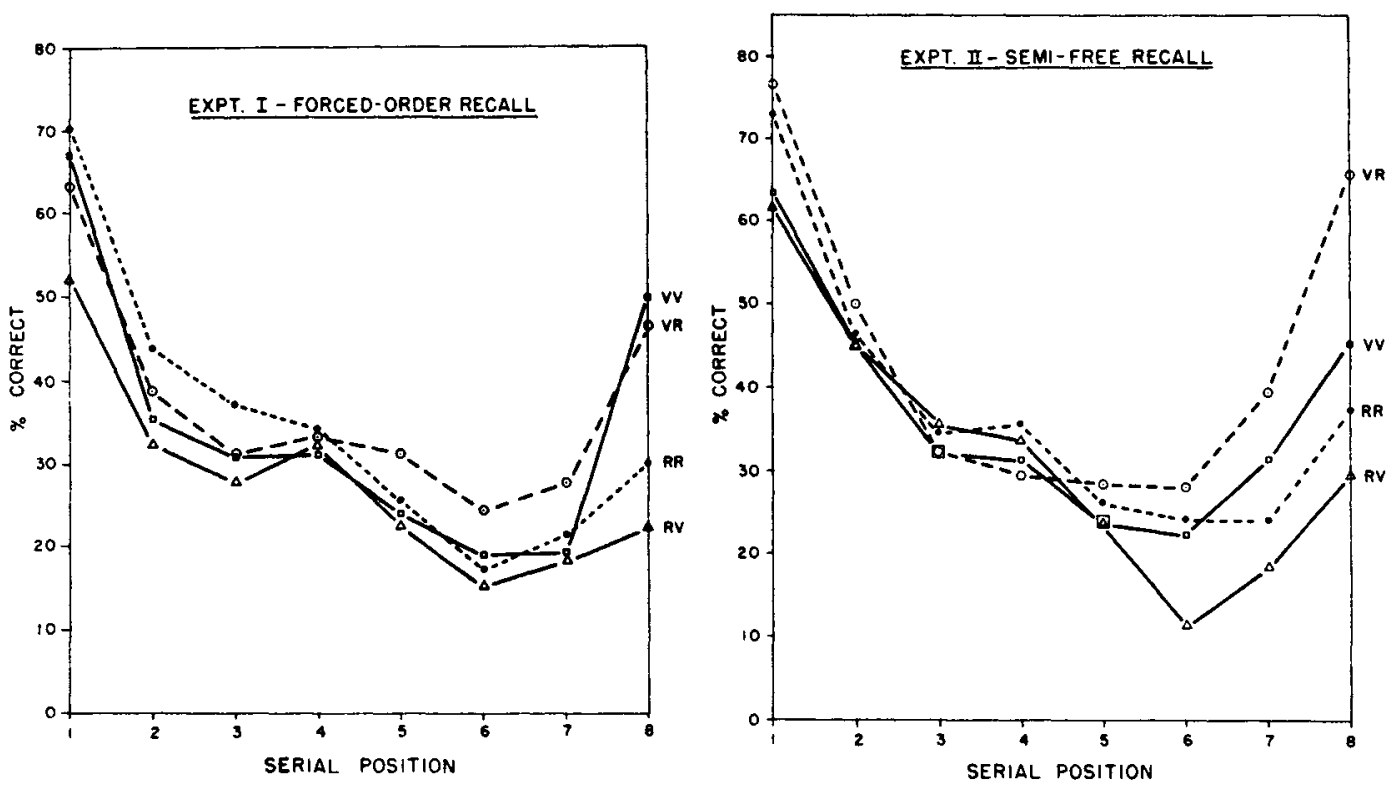

Fig. 1. Percentage correctly recalled as a function of presentation-mode, rehearsal-mode, and serial position, in Experiments $I$ and II.

several Ss resorted to the strategy of recalling the last items first.

On semi-free recall, then, the major difference between recall following voiced as opposed to unvoiced rehearsal was reflected in greater recency effects for the latter condition. On forced recall, this difference was reduced. For both types of recallorder, voiced rehearsal was overall less efficient than was unvoiced rehearsal. It can therefore be inferred that, provided recall is given in forced order, the main drawback to investigating rehearsal-processes by analyzing "overt" rehearsal will be that the total amount recalled will be reduced under the "overt" condition. But apart from this, there were no differences of apparent importance with respect to serial position effects, nor did the mode of rehearsal interact with the mode of presentation. It may be concluded therefore that an analysis of "overt" rehearsal can be validly used as a means of indirectly examining what might be expected to occur in subvocal rehearsal, if recall is forced-order. If recall is semi-free in order, the method is less reliable.
A more detailed analysis of "overt" rehearsal in a forced-order recall situation is currently in preparation.

The reasons why voiced rehearsal gave lower overall recall than did unvoiced rehearsal, in both experiments, are probably several. Voicing takes longer, leaving more time for the forgetting of items yet to be rehearsed; the attention devoted to the speakingact may itself prevent rapid subvocal rehearsal; voiced items might set up more proactive or retroactive inhibition. Some results in the 1966 paper also suggested that it was less easy to manipulate strategies of recall if recall had to be voiced.

\section{Reference}

Murray, D. J. Vocalization at presentation and immediate recall, with varying recall methods. Quart. J. exp. Psychol., 1966, 18, 9-18.

\section{Note}

1. This work was supported by N.R.C. Operating Grant APB-126. I am most grateful to $M$. Norris for research assistance. 